\title{
Concomitant and neoadjuvant chemotherapy for cervical cancer
}

\author{
Jayne F Tierney ${ }^{1}$, Claire Vale ${ }^{1}$, Paul Symonds ${ }^{2}$
}

1. Meta-analysis Group, MRC Clinical Trials Unit, London, UK

2. Department of Cancer Studies and Molecular Medicine, University of Leicester, UK

Author for correspondence

Dr. JF Tierney

Address: $\quad$ Meta-analysis Group, MRC Clinical Trials Unit, 222 Euston Road, London, NW1 2DA, UK.

Tel: $\quad$ +44(0)207670 $\quad$ 4724

Fax: $\quad+44(0) 2076704816$

E-mail: j.tierney@ctu.mrc.ac.uk 


\begin{abstract}
In the past, women with early stage cervical cancer have been treated with radical radiotherapy or radical surgery, and women with locally advanced disease with radical radiotherapy, each offering a good chance of cure. Numerous trials have investigated whether giving cytotoxic chemotherapy alongside radiotherapy or prior to local treatment could augment the established benefits of these therapies, and are reviewed here. There is a strong basis for the use of platinum-based chemoradiotherapy, the current standard of care, but little convincing evidence as to the therapeutic benefits of using concomitant hydroxyurea. Chemoradiotherapy based on other non-platinum agents may offer alternatives. The effect of chemoradiotherapy appears to vary according to the stage of disease, but all types of women benefit. Neoadjuvant chemotherapy prior to radiotherapy could jeopardise survival and should be avoided unless perhaps a 'quick', dose intense regimen is used. Neoadjuvant chemotherapy before surgery may be beneficial, but the approach will remain controversial until it is tested against platinum-based chemoradiotherapy. Future studies many include combinations of other cytotoxics such as topotecan with cisplatin-based concomitant chemoradiotherapy or the addition of agents targeted against specific receptors such as EGFR.
\end{abstract}

\title{
Keywords
}

Review; Systematic review; Randomised controlled trials; Cervix neoplasms; Drug therapy; Neoadjuvant; Radiotherapy; 


\section{Introduction}

The incidence of cervical cancer and associated mortality has declined in North America, parts of Europe, Australia and New Zealand largely as a result of effective screening [1];[2];[3]. On a global scale however, it is the second most common cancer in women, and is the most prevalent female malignancy in many developing countries [1].

Most patients in the developed world present with early disease either confined to the cervix or with limited extension beyond it (FIGO stage IB1-IIA) and, in the past, were usually treated with radical radiotherapy or radical hysterectomy plus node dissection. Women with locally advanced disease (FIGO stage IIB, III, IVA and 1B bulky), tended to be treated with radical radiotherapy, comprising external beam and intracavitary treatment. Radical radiotherapy also provided an alternative to radical surgery for patients with tumours larger than 4cms confined to the cervix (FIGO stage IB 'bulky' or IB2) [4].

Although, offering a good chance of cure, surgery was restricted to early operable tumours and the maximum radiation dose in advanced disease was limited by tolerance of normal tissues. This necessitated the investigation of additional therapies that might augment the well-established benefits of surgery and radiotherapy. Using chemotherapy concurrently with definitive radiotherapy could increase sensitivity of tumours to the effects of radiotherapy, improving local control and, if the dose of chemotherapy was sufficiently cytotoxic, it could also have a systemic effect. Giving chemotherapy prior to surgery could render inoperable tumours (FIGO stage IIB-IIIB) operable and treat metastases. Instead, the use of chemotherapy before radiotherapy could reduce tumour size and control micrometastatic disease with potentially less toxicity than chemotherapy that is concomitant to local treatment. Not surprisingly then these approaches have been the subject of investigation in randomised trials for around 40 years. Their effects to date are summarised here, based on existing systematic reviews, and randomised trials identified through 
searches of Medline, the PDQ Cancer Clinical Trials Registry and Proceedings of the American Society of Clinical Oncology.

\section{Concomitant cytotoxic chemotherapy and radical radiotherapy versus radical} radiotherapy

Hydroxyurea-based chemotherapy

Following pre-clinical studies showing the potentiating effects of hydroxyurea on radiotherapy, seven randomised trials were initiated to compare hydroxyurea-based chemoradiotherapy with radiotherapy alone (Table 1). In total 532 women with FIGO stages IIB-IVA were included, and the hydroxyurea was adiministered at a dose of $80 \mathrm{mg} / \mathrm{m}^{2}$ either every three days or thrice weekly for 12 weeks. External beam radiotherapy varied from 40 to 69 Gy and intracavitary radiotherapy from 23-40Gy.

Some of these trials concluded that there were benefits associated with adding hydroxyurea to radiotherapy [5];[6];[7];[8]. However, a systematic review based on data extracted from the trial reports questioned these conclusions, because of major methodological deficiencies in some trials and an inability to assess the methodology of others [9]. Five of the trials [6];[10] included less than 50 patients making them extremely underpowered. Moreover, women were excluded ad hoc from the analyses of most trials, sometimes for reasons relating to both treatment and outcome, such that the reported estimates of effect may be biased. This particularly affects the largest trial [10] where nearly half of the patients were excluded, many because of treatment related complications and some because of progressive disease. Similarly, Piver [7] appeared to exclude treatmentrelated deaths from the hydroxyurea group. Inconsistent definition of outcomes and their possible selective reporting, as well as patient selection were additional factors that could have given a skewed impression of the effects of hydroxyurea, such that the results of these trials were not pooled in a meta-analysis [9]. Hydroxyurea does appear to increase acute gastrointestinal, bone marrow and white blood toxicity sometimes leading to discontinuation 
of treatment and even death. Thus, the authors concluded that there is no reliable or convincing evidence as to the therapeutic benefits of hydroxyurea and commented that despite being easy to administer, it has not become a standard therapy alongside radiotherapy [9].

\section{Other cytotoxic chemotherapy}

In 1999, five trials were published, each showing a substantial survival benefit associated with concomitant cisplatin-based chemoradiation [11];[12];[13];[14];[15] prompted the US National Cancer Institute $(\mathrm{NCl})$ to issue a clinical alert, recommending that "that strong consideration should be given to adding concurrent chemotherapy to radiation therapy in the treatment of invasive cervical cancer". This has led to cisplatin-based chemoradiation becoming a standard of care, as adjuvant therapy for high-risk early disease, and instead of radical radiotherapy for locally advanced disease.

Recognising that these trials differed in terms of the local and experimental treatments used and the stages of disease included, and that they represented only a subset of the relevant trials, a systematic review of published and other summary data attempted to summarise the effects of chemoradiotherapy based on all trials [16]. Nineteen trials were identified, 16 of which compared chemoradiotherapy with the same radiotherapy (Table 2). One further trial compared chemoradiotherapy with extended field radiotherapy [11] and two trials compared cisplatin-based chemoradiotherapy with hydroxyurea-based chemoradiotherapy [12];[14]. Together these trials included 4580 women that had mostly FIGO stage IIB-IVA cervical cancer [16], but some included, or were confined to, women with earlier stages of disease (IA-IIA). Also, around half the trials restricted entry to women without para-aortic node involvement. Ten of the trials used platinum (usually cisplatin) either weekly as a single agent, or every 2-6 week in combination with 5-fluorouracil (5-FU), vincristine or bleomycin. The total platinum dose was between 40 and $280 \mathrm{mg} / \mathrm{m}^{2}$. The remaining seven trials used trials used 5-FU either as a single agent or in combination with 
Mitomycin- $\mathrm{C}$, or Mitcomycin- $\mathrm{C}$ either as a single agent or in combination with bleomycin or epirubicin.

Depending on the outcome information 11 to 13 trials (62 to $78 \%$ of patients) was available for the meta-analysis. Based on these data, there was a significant $29 \%$ reduction in the relative risk of death with chemoradiotherapy $(\mathrm{HR}=0.71,95 \% \mathrm{Cl}=0.63-0.81, \mathrm{p}<0.001)$, equivalent to an approximate $12 \%$ absolute improvement in survival. There was greater evidence of benefit in the trials using platinum-based chemotherapy $(\mathrm{HR}=0.70,95 \% \mathrm{Cl}=0.61$ $0.80, p<0.001)$, rather than those that used non-platinum based chemotherapy $(H R=0.81$, 95\% $\mathrm{Cl}=0.56-1.16, \mathrm{p}=0.20$ ), but there was no clear evidence of a difference in the size of effect between these two groups $(p=0.48)$. The high level of statistical heterogeneity associated with these results $(p=0.009)$ could not be explained by the scheduling or frequency of chemotherapy, or the use of hydroxyurea in the control group. An exploratory analysis suggested that the effect of chemoradiotherapy might be greater in those trials randomising a large proportion of stage I and II patients. However, none of these analyses fully explained the heterogeneity observed [16].

Results for disease-free survival, and rates of local and distant recurrence, were also significantly and substantially in favour of chemoradiotherapy, but again heterogeneity of trial results was apparent [16]. Furthermore, the benefits were at the expense of increased serious (grade 3 or 4), acute haematological (white blood cell, haemoglobin, platelet or not otherwise specified) and gastrointestinal toxicity. However, late toxicity was only systematically recorded in three of the included trials and was defined differently across these trials, making it difficult to assess the impact of chemoradiotherapy on this outcome.

A subsequent systematic review and meta-analysis investigating the effects of cisplatin-based chemoradiotherapy used a slightly different set of trials and was based on death rates [17] (rather than the duration of survival as described above). Nevertheless, it demonstrated a significant reduction in the risk of death across all trials ( $R R=0.64,95 \%$ 
$\mathrm{Cl}=0.64-0.86)$, and in the trials that included only women with locally advanced disease $(\mathrm{RR}=0.74,95 \% \mathrm{Cl}=0.64-0.86)$ or high-risk, early disease $(0.56,95 \% \mathrm{Cl}=0.41-0.77)$. The effect of chemoradiotherapy persisted when trials were grouped according to the use of hydroxyurea on control and single agent or combination chemotherapy.

While both systematic reviews further confirmed the benefits of adding to chemotherapy to radiotherapy on outcome, issues were raised and questions remained. The first systematic review [16] incorporated more trials than any previous or summary of chemoradiotherapy, but even then not all trials were included, follow-up was variable and the differences between results could not be explained. Many of the women in the trials had early-stage disease and a number of trials actively excluded women with involved paraortic nodes, such that the impact of chemoradiotherapy on more advanced or poorer prognosis disease was less clear. A major finding was that chemoradiotherapy appeared to have a systematic as well a local effect, but a significant reduction in metastases was not seen when this review was updated to include more trials and further follow-up [18]. Also, any potential adverse effects of chemoradiotherapy in the long term could not be assessed. The second review [17] highlighted the difficulties of interpreting the effects of cisplatin-based chemoradiotherapy when the included trials used different chemotherapy agents and regimens, as well as different control treatments.

A systematic review and meta-analysis based on IPD has been initiated to more fully review all the existing evidence. As the quality of data and analysis is improved with this approach, it is regarded as the gold standard of systematic review [19]. Preliminary results of the meta-analysis were presented in 2006 [20] and updated results in 2007 [21]. Although not all relevant trials were included (Table 3), the most recent presentation was based on data from 17 trials and 4638 women [21]. Excluding the trial that gave extended-field radiotherapy [11];[22] or hydroxyurea [12];[14] on the control arm or additional chemotherapy in the treatment arm [15];[23];[24] thereby leaving only the trials that compared chemoradiotherapy with the same radiotherapy, there was a $21 \%$ relative reduction in the 
risk of death $(\mathrm{HR}=0.79,95 \% \mathrm{Cl}=0.70-0.90, \mathrm{p}=0.0003)$. This is equivalent to a $7 \%$ absolute improvement in 5-year survival. The benefits were similar in the trials using platinum and non-platinum chemoradiotherapy. Although the analyses were limited in power, there was no clear evidence of differences in effect according to radiotherapy or chemotherapy dose or scheduling. There was however, a suggestion that the size of benefit of chemoradiotherapy varied according to stage, but not other patient characteristics. Acute haematological and gastrointestinal toxicity was again found to increase with the addition of chemotherapy to radiotherapy, but even with IPD there was insufficient data to establish whether long-term side effects were exacerbated. By analysing the results of trials that were not confounded by the use of additional treatments on the control or treatment arms, this IPD meta-analysis has given a more reliable and readily interpretable estimate of the effect of concomitant chemotherapy and radiotherapy [21]. While this is smaller than previously suggested [16];[17], a benefit persists, even with the inclusion of more trials and patients than any previous review, and a full publication is awaited.

Although the review of IPD found a benefit of chemoradiotherapy for all stages of disease it was based on a relatively small proportion of women with advanced stages (FIGO III-IV. Thus, the data do not represent well the cervical cancer population in the developing world, where as many as half of women present with advanced disease. Thus, in India, where cisplatin is an available and affordable drug, a large trial has been initiated comparing weekly cisplatin-based chemoradiotherapy with radiotherapy alone in women with FIGO stage IIIB cervical cancer (TMH/114/2003/CRCAX, NCT00193739, Table 3). If this trial, due for completion in 2008, reaches its planned recruitment target of 850 women, it should provide a clear indication of the effects of chemoradiotherapy in advanced cervical cancer.

While weekly single-agent cisplatin chemoradiotherapy has become a standard of care, it may not be the optimal chemotherapy regimen or schedule. A completed trial has randomised 33 women with locally advanced disease to receive either weekly cisplatin or paclitaxel during radiotherapy [25]. Although there is no significant difference between the 
drugs in terms of local control and survival, the small size of this trial prevents this being concluded definitively. A large trial presented recently [26] has compared the effects of four different non-platinum regimens concomitant to radiotherapy in 921 women, also with locally advanced disease. With a median follow-up of approximately 50 months, 5-FU, two 5FU/mitomycin C combinations and hydroxyurea all give broadly similar progression-free survival and overall survival results that appear comparable to those from standard cisplatinbased chemoradiotherapy. A full report with further follow-up and a comparison of late effects late effects is awaited. An ongoing trial in women with FIGO stage IB2-IVA cervical cancer (NCT00548821) should establish whether three-weekly cisplatin-based chemoradiotherapy can offer any gains in terms of acute or late toxicity, quality of life or progression-free survival, over standard weekly cisplatin.

Other ongoing randomised trials are investigating ways of enhancing the benefits of standard weekly cisplatin-based chemoradiotherapy. For example one trial adds tirapazamine (GOG 0219, NCT00262821), which is selectively toxic to hypoxic cells and another is using hyperthermia, which may have a lethal impact on tumours cells, as well as increasing their sensitivity to radiotherapy and/or chemotherapy (DUMC 451604 2RIER, NCT00085631). It remains to be seen whether these alternative approaches can further increase the benefits associated with chemoradiotherapy.

\section{Neoadjuvant chemotherapy prior to radical radiotherapy versus radical radiotherapy}

A systematic review and meta-analysis based on individual patient data (IPD) identified 21 eligible trials that compared neoadjuvant chemotherapy plus radical with radical radiotherapy [27], 18 of which were included in the analysis (Table 3). In certain trials, a small number of women had radical surgery as an alternative to radical radiotherapy [28];[29], and in another most women had radical surgery followed by adjuvant radiotherapy [30]. Most of the 2074 women in the trials had FIGO stage II-III tumours, but some trials included women with stage IB disease. Cisplatin was the main drug in all the neoadjuvant 
chemotherapy regimens, with a planned total dose of between 100 and $320 \mathrm{mg} / \mathrm{m} 2$ in 10 to 28 day cycles. The external beam radiotherapy and intracavitary radiotherapy dose was quite variable, with a total dose in the range 55 to $80 \mathrm{~Gy}$.

When all trials were combined, a highly significant degree of heterogeneity was evident, suggesting that the trials might not be addressing quite the same question and that pooling across all trials was inappropriate [27]. However, the authors were able to explain some of the heterogeneity through pre-specified analyses that grouped trials by chemotherapy cycle length ( $\leq 14$ day cycles, $>14$ day cycles), and planned cisplatin dose intensity $\left(<25 \mathrm{mg} / \mathrm{m}^{2}\right.$ per week, $\geq 25 \mathrm{mg} / \mathrm{m}^{2}$ per week). When trials were grouped by chemotherapy cycle length there was a significant difference in the direction of the effect $(p=0.0009)$. The group of trials using cycles lasting longer than 14 days showed a significant $25 \%$ increase in the relative risk of death with neoadjuvant chemotherapy ( $H R=1.25,95 \%$ $\mathrm{Cl}=1.07-1.46), \mathrm{p}=0.005)$, representing an absolute $8 \%$ reduction in 5 -year survival. With shorter chemotherapy cycle lengths, a significant $17 \%$ decrease in the relative risk of death was seen $(\mathrm{HR}=0.83,95 \% \mathrm{Cl}=0.69-1.00, \mathrm{p}=0.046)$, equivalent to an absolute improvement in 5-year survival of $7 \%$. However, there was still significant heterogeneity in this short chemotherapy cycle group $(p=0.002)$ that was only reduced $(p=0.193)$ when a small trial with an extreme result [29] was excluded from the analysis.

Similar variability in the effect of neoadjuvant chemotherapy $(p=0.002)$ was observed when trials were grouped by planned cisplatin dose intensity [27]. There was a significant $35 \%$ increase in the risk of death in trials that used less than $25 \mathrm{mg} / \mathrm{m}^{2}$ per week $(H R=1.35$, 95\% $\mathrm{Cl}=1.11-1.64, \mathrm{p}=0.002)$, reducing absolute 5 -year survival by $11 \%$, and no evidence of heterogeneity. However, the results for the higher dose intensity group were less clear, with only a trend for increased survival (HR=0.91, 95\% $\mathrm{Cl} 0.78-1.05, \mathrm{p}=0.200)$ and still considerable heterogeneity $(p=0.001)$. Grouping trials by other characteristics (total cisplatin dose, use of surgery as part of local treatment or use of adjuvant chemotherapy) did not explain the heterogeneity in the survival results further. Results for locoregional disease-free 
survival, metastases-free survival and overall disease-free survival followed a similar pattern to those for survival.

Subgroup analyses were carried out within the trial groups defined by the chemotherapy cycle length, where heterogeneity was less, but this limited power. Nevertheless, there was no evidence to suggest that chemotherapy was differentially effective by age, histology or performance status in either trial group [27].

Late toxicity data was only available for around half the trials and within these there were a relatively small number of late effects on the bladder (91), intestine (117) and vagina (79) and a formal comparison of late toxicity by arm was not carried out [27].

Two unpublished trials and one published trial [31] could not be included in the IPD meta-analysis and another has been completed since radiotherapy alone [32] (Table 4). Detailed information is only available for the published trials. Kumar [31] randomised 72 women with stage IIIB cervical cancer to three cycles of cisplatin-based BIP prior to radiotherapy, with a planned cisplatin total dose of $150 \mathrm{mg} / \mathrm{m}^{2}$. There was no significant difference in 2-year survival with neoadjuvant chemotherapy (71\%) compared to control (69\%). The other trial [32] included 61 women with stage IIIB or IVA cervical carcinoma and gave three cycles BOMP neoadjuvant chemotherapy every four weeks, giving a cisplatin total dose of $210 \mathrm{mg} / \mathrm{m}^{2}$. Again there was no significant difference in survival (calculated from the end of therapy) between the two groups ( $p=0.61)$, with an estimated HR [33];[34] of $0.93(95 \% \mathrm{Cl}=0.43-2.04)$ and also, no significant difference in the incidence of distant metastases $(p=0.46)$. While these published results do not suggest particular harm or benefit from neoadjuvant chemotherapy, neither trial was large enough to reliably exclude either possibility. Both trials gave a cisplatin dose intensity of less than $25 \mathrm{mg} / \mathrm{m}^{2} /$ week and had chemotherapy cycles longer than 14 days, but because of their relatively small size, their inclusion in the meta-analysis, would be unlikely to alter its conclusions. 
The authors offer various potential explanations for the observation that more protracted or less dose intense chemotherapy was detrimental for survival and recurrence, and shorter cycle length and/or higher dose intensity neoadjuvant chemotherapy might be advantageous. They suggested that in these rapidly proliferating tumours [35], with a relatively high growth fraction [36], long cycle and/or low dose-intensity chemotherapy may not be effective in reducing repopulation with radiotherapy resistant cells. Alternatively, if prolongation of the duration of radiotherapy reduces local control by allowing extra time for repopulation with resistant cells [37] and there is chemotherapy and radiotherapy crossresistance, the duration of chemotherapy, delay to radiotherapy and duration of radiotherapy, could each have an impact on prognosis. This is pertinent because those trials giving more prolonged chemotherapy tended to be those with longer delays to, and longer durations of, radiotherapy [27]. Of course, the impact of drugs other than cisplatin or other known or unknown characteristics of the trials or patients may better explain the heterogeneity in trials results, or perhaps the patterns found are chance findings.

\section{Neoadjuvant chemotherapy prior to radical surgery versus radical radiotherapy}

A systematic review and meta-analysis based on IPD identified six trials (Table 4) that compared chemotherapy prior to surgery with radical radiotherapy and data from five of these was available for analysis [27]. Only 872 women were included, mostly with FIGO stage IB-IIA tumours, although more advanced stages were sometimes eligible. The trials used between 2-7 cycles of cisplatin-based combination chemotherapy prior to radical hysterectomy and lymphadenectomy and the radiotherapy regimens in the control arms were similar. Together these trials gave a highly significant $(\mathrm{HR}=0.65,95 \% \mathrm{Cl}=0.53-0.80$, $\mathrm{p}=0.0004) 35 \%$ reduction in the relative risk of death, with neoadjuvant chemotherapy, but with some modest heterogeneity $(p=0.06)$. These results translate into a $14 \%$ absolute improvement in 5-year survival and this effect did not appear to vary according to age, stage, histology, grade or performance status. Similar benefits were seen for local, distant and 
overall disease-free survival, but in the case of locoregional disease-free survival, there were more substantial inconsistencies in effect between trials $(p=0.005)$.

A number of factors may explain these differences and make interpretation difficult. Intra-arterial chemotherapy was used in one trial [38], which may not be entirely comparable with the intravenous route. More importantly perhaps, in the neoadjuvant chemotherapy group, additional pelvic radiotherapy was given to most of the women in two trials [39],[40] and to around $30 \%$ of women in another two trials [38];[41]. This makes it difficult to assess the precise benefit associated with the neoadjuvant chemotherapy plus surgery in comparison with radical radiotherapy. Moreover, this approach now must compete with concomitant chemoradiotherapy, the current standard of care for this group of women and the more appropriate comparator.

\section{Neoadjuvant chemotherapy prior to radical surgery versus radical surgery}

In more recent years randomised trials have examined whether giving cisplatin-based neoadjuvant chemotherapy prior to radical hysterectomy and pelvic lymphadenectomy, can improve outcome compared with surgery alone [42];[43];[44];[45] Table 5).

One trial randomised 192 women with FIGO stage IB-IIIB tumours to three cycles of PVB chemotherapy every three weeks, with a total planned dose of cisplatin was $150 \mathrm{mg} / \mathrm{m}^{2}$ or to no chemotherapy [42]. Women in both groups had a modified radical hysterectomy, unless they were in the control group and had a stage IIIB tumour, or were in the neoadjuvant group and had stage IIIB tumour that did not respond to chemotherapy. In these cases the women instead received radical radiotherapy. Also, those that had radical surgery, but had parametrial infiltration or were lymph node positive, were given adjuvant radiotherapy. The overall response to chemotherapy was $79 \%$, and $96 \%$ of women in the neoadjuvant chemotherapy group and $81 \%$ in the control group, had a radical hysterectomy. In these surgical patients, around a third also received adjuvant radiotherapy. Although many subgroup analyses were reported, there was no significant difference in either disease- 
free survival or overall survival by treatment group [42] and we estimate [33];[34] that there are wide confidence intervals around the HR for survival making it unreliable (HR=0.87, 95\% $\mathrm{Cl}=0.53-1.44)$

Another trial included 106 women with stage IB tumours and compared two cycles of cisplatin and 5-FU at 3-weekly intervals plus radical hysterectomy with radical hysterectomy [43]. The total planned cisplatin dose was $150 \mathrm{mg} / \mathrm{m}^{2}$. Women, who at surgery were found to have deep cervical invasion or positive lymph nodes, were also given pelvic radiotherapy. The response rate was high (84.6\%) and all women had surgery, with $61 \%$ in the neoadjuvant arm and $54 \%$ in the control arm also receiving adjuvant radiotherapy. Significantly fewer lymph node metastases were detected in the neoadjuvant chemotherapy compared to the control group (9.6\% versus $29.6 \%, p=0.024)$ and both survival and diseasefree survival were improved by neoadjuvant chemotherapy, with estimated relative risk reductions [33];[34] of $32 \%$ and $(H R=0.58,95 \% C=0.38-0.88, p=0.0112)$ and $26 \%(H R=0.64$, $95 \% \mathrm{Cl}=0.41-0.99,0.044)$ respectively.

A third trial randomised 134 women with bulky stage IB-IIA or IIB tumours, and compared two to four cycles BOMP chemotherapy every 3 weeks followed by radical hysterectomy with radical hysterectomy, giving a total planned dose of cisplatin of between 140 and $360 \mathrm{mg} / \mathrm{m}^{2}$ [44]. Those with positive surgical margins, metastatic nodes, and infiltration of the parametrium and/or deep myometrial invasion also received post-operative pelvic radiotherapy. The response to neoadjuvant chemotherapy (61\%) did not seem to increase operability and the trial was stopped early because an interim analysis of 108 patients suggested that survival was inferior $(\mathrm{HR}=2.11,95 \% \mathrm{Cl}=0.52-8.49)$. Although, not a statistically significant result, the authors concluded that it was very unlikely that it would be overturned in favour of neoadjuvant chemotherapy.

A fourth trial compared $50 \mathrm{mg} / \mathrm{m}^{2}$ of cisplatin and $1 \mathrm{mg} / \mathrm{m}^{2}$ of vincristine chemotherapy every 10 days for 3 cycles prior to radical hysterectomy and pelvic/para-aortic 
lymphadenectomy with the same surgery. A total of 291 women with bulky stage IB cervical cancer were included [45]. Women in both arms who were found at surgery to have positive pelvic nodes, parametrial margins or positive para-aortic nodes were also given pelvic or extended-field radiotherapy. Operability was very similar in the neaodjuvant chemotherapy (77\%) and control arms (78\%), but there was some disparity in the administration of postoperative radiotherapy to women, being $52 \%$ and $45 \%$ of women respectively. Neoadjuvant chemotherapy did not confer any benefit on progression-free survival $(\mathrm{HR}=0.998$, estimated [33];[34] 95\% Cl=0.70-1.42) or survival ( $\mathrm{HR}=1.008$, estimated [33];[34] 95\% Cl=0.69-1.48). This trial also stopped early, this time due to poor accrual and considerable use of radiotherapy off protocol, reaching only $70 \%$ of its target recruitment. Nevertheless, the authors concluded that it is unlikely that additional data would alter these results.

These trials provide the best opportunity to assess the effect of adding neoadjuvant chemotherapy to surgery, but only one found a survival benefit from neoadjuvant chemotherapy [43], and the others either found no overall benefit [42],[45] or a detriment from this treatment [44]. Operability was only increased in one trial [42] and adjuvant radiotherapy was given to between approximately 30 to $60 \%$ of women in these trials. Although a comprehensive and systematic review of all relevant trials is probably required to make sense of the contradictory findings, the weight of evidence from these trials does not appear to support adding neoadjuvant chemotherapy to surgery. Moreover, for chemotherapy followed by radical hysterectomy to be considered as a valid alternative to the current therapeutic standard of weekly cisplatin based chemoradiotherapy, a head to head randomised comparison is required.

\section{Concomitant cytotoxic chemotherapy and radiotherapy versus neoadjuvant chemotherapy prior to surgery}

We have identified two ongoing randomised trials that are comparing chemoradiotherapy with chemotherapy prior to radical surgery. The EORTC trial of plans to 
recruit 686 women with FIGO stage IB2, IIA >4cm and IIB cervical cancer and compare weekly cisplatin-based chemoradiotherapy with at least 3 cycles of cisplatin-based chemotherapy, followed by radical hysterectomy with (EORTC 55994, NCT000393380). Survival is the primary outcome, with progression-free survival, response, toxicity and quality of life as secondary outcomes. The Tata Memorial Hospital is running a similar trial, randomising 730 women, again with stage IB2-IIB disease and comparing weekly cisplatinbased chemoradiotherapy with 3 cycles of carboplatin and paclitaxel neoadjuvant chemotherapy plus radical hysterectomy (NCT00193739). The primary outcomes of this trial are disease-free survival and overall survival and the secondary outcomes are the rate of metastases and morbidity. In each trial women found at surgery to have risk factors for recurrence are also given adjuvant radiotherapy or chemoradiotherapy.

If these trials reached their planned recruitment targets they should establish definitively the relative merits of these two commonly used approaches in terms of survival and recurrence. Importantly, it will be possible to place these results in the context of their respective side effects and their consequent impact of on quality of life, issues that have not been fully addressed in most of chemoradiotherapy or neoadjuvant chemotherapy trials reviewed here.

\section{Discussion}

Numerous randomised trials and subsequent systematic reviews have investigated whether using cytotoxic chemotherapy either alongside radiotherapy or in advance of local treatment improves outcome in cervical cancer. Undoubtedly, the biggest advance has come from combining chemotherapy concomitantly with radiotherapy. The publication of five large trials, each showing a benefit associated with cisplatin-based chemoradiotherapy, prompted a rare $\mathrm{NCl}$ alert that has led to dramatic and widespread uptake of concomitant chemoradiotherapy in practice, as either definitive or adjuvant therapy $[46] ;[47] ;[48] ;[49]$. Cisplatin is the most commonly used drug [46];[48], usually administered weekly [48], as a 
single agent [48] [49], and this is supported by the evidence to date [16];[17];[21]. In addition, the use of chemoradiotherapy based on cisplatin combinations [49];[49];[46], non-platinum drugs, such as 5-FU, or non-platinum combinations [49] also seems reasonably evidencebased [21]. One randomised trial directly comparing cisplatin with 5FU-based chemoradiotherapy closed early after interim analyses showed higher rates of progression with 5-FU [50], but was no longer powered to detect a difference in progression-free or overall survival, and so is inconclusive in this regard. The use of hydoxyurea as single agent in practice [46] is not adequately supported by the older trials [9], but emerging trial evidence may counter this view [26].

Importantly, the implementation of chemoradiotherapy in practice has been associated with an estimated 5 to $8 \%$ increase in 3-year survival at the population level [47];[49]. This is of similar in magnitude to the $7 \%$ absolute 5 -year survival benefit seen in the most recent synthesis of the chemoradiotherapy trials [21]. It is re-assuring that chemoradiotherapy has been found to improve survival in all stages of disease [21]. However, as the size of benefit seems to vary by stage [21], the impact on cervical cancer mortality is likely to vary in different regions of the world, according to the stages that predominate at diagnosis. Although the absolute survival benefit seen currently [21] is smaller than initially suggested [16], it remains clinically worthwhile assuming it is not at the expense of excess late toxicity or poorer quality of life in this relatively young group of women, which has yet to be established conclusively.

Neoadjuvant chemotherapy prior to radiotherapy has been used in the past when waiting times for definitive radiotherapy were long and continues to be used where access to radiotherapy is remains problematic. Results of the IPD meta-analysis [27] suggest that this practice could jeopardise survival and should be avoided unless perhaps a 'quick', dose intense regimen is used. A more attractive concept perhaps, is the combination of a short intensive neoadjuvant chemotherapy schedule before standard cisplatin-based chemoradiotherapy, which is the basis for an ongoing UK phase II trial (UCLCTC- 
BRD/05/22-CERVIX, NCT00462397). Women receive 6 weekly pulses of carboplatin and paclitaxel followed by radical radiotherapy and concomitant weekly cisplatin. Although anecdotal, patients recruited by one of authors (PS) seem to have had significant tumour shrinkage with neoadjuvant carboplatin and paclitaxel, which is well tolerated. However, recruitment has been hampered, because some women are reluctant to enter the trial with the prospect of hair loss, treatment of 3 months rather than 6 weeks duration, and the lack of evidence, at present, for benefit despite additional toxicity.

While there appears to be survival benefits associated with giving neoadjuvant chemotherapy and surgery rather than radical radiotherapy, data from most of the trials of chemotherapy prior to surgery compared with surgery alone were less convincing. Many women in the neoadjuvant arms of all of these trials also received adjuvant radiotherapy, thus prolonging their treatment and potentially exacerbating associated morbidity. More recent trials have attempted to define a better neoadjuvant regimen than those used previously [51], but it may be that the theoretical rationale for its use in cervical cancer is flawed [52]. How neoadjuvant chemotherapy followed by surgery fares in comparison to the current standard of chemoradiaotherapy in the two ongoing trials is likely to ultimately decide its future.

Chemotherapy could be given after local therapy in patients with a higher risk of systemic relapse. Two trials of additional chemotherapy given after chemoradiotherapy [24] or surgery and postoperative chemoradiotherapy [23] show a marked survival advantage. In the SWOG trial [23], this advantage appeared more pronounced in the patients who received 3 or 4 cycles of chemotherapy. A re-analysis of more mature data in 2005 [53] showed maximal benefit for patients with spread to 2 or more lymph nodes following postoperative radiotherapy and adjuvant chemotherapy compared to those receiving only postoperative radiotherapy (5-year survival 55\% versus $75 \%$ ). Adjuvant chemotherapy added only a $5 \%$ or less 5-year survival improvement for patients with lower risk factors such as only 1 lymph node being involved in cancer or a tumour size of $2 \mathrm{~cm}$ or less in diameter. Interestingly, the 
number of cycles of chemotherapy was not taken into account in the most recent analysis [53]. Adjuvant chemotherapy trials after extensive surgery, especially when patients have also had postoperative radiotherapy are hard to conduct, because many patients will not agree to participate. Typical examples are trials of adjuvant chemotherapy following cystectomy for bladder cancer. Poor recruitment resulted in all six trials published to date to being significantly underpowered [54].

An obvious way forward is to add either other cytotoxic or biological agents to current radiotherapy and cisplatin schedules. One potential problem is that if full doses of cisplatin are used, extra toxicity may limit the dose of any second agent. This was seen when the orally administered 5-FU pro-drug capecitabine was given together with full dose cisplatin (40mg/m² weekly) in a phase II study. The maximum tolerated daily dose was only $300 \mathrm{mg} / \mathrm{m}^{2} /$ bid [55]. A 3-weekly schedule of topotecan and cisplatin was shown to offer a modest but significant survival advantage compared to cisplatin alone when used to treat patients with metastatic disease, in the Gynecology Oncology Group (GOG) Trial 179 [56]. Thus, topotecan would seem to be a prime candidate for inclusion alongside cisplatin in primary treatment schedules. Both agents can be given weekly and significantly, when topotecan is given weekly for the treatment of ovarian cancer, it has been shown to be much less myelotoxic than when given in the usual 3-weekly schedule [57]. An ongoing phase II trial is investigating the efficacy of weekly cisplatin and topotecan combined with radiotherapy in bulky early stage and locally advanced stages (UCI 03-33, NCT00257816). Possibly, the addition of other cytotoxic drugs to cisplatin will offer, at best, a modest increase in efficacy, as for example, in GOG trial 120 [14], weekly cisplatin seemed as effective as a 3-weekly schedule of cisplatin 5-FU and hydroxyurea.

An alternative approach is the use of newer biological agents aimed at specific receptors. An obvious target is the epithelial growth factor receptor (EGFR), as high levels of EGFR have been detected both in biopsy material [58] and cell lines derived from biopsies, particularly those from recurrent or metastatic disease [59]. Moreover, in several studies, 
elevated levels of EGFR have been correlated with aggressive biological behaviour and poorer prognosis [60];[61]. Cervical cancer and squamous cancer arising in the mucous membranes of the head and neck have many biological features in common. It is therefore noteworthy that a combination of cetuximab, a monoclonal antibody against EGFR, and radical radiotherapy has been shown to improve survival amongst patients with locoregionally advanced cancer of the head and neck when compared to radical radiotherapy alone. In this randomised controlled trial [62], the addition of cetuximab increased both median survival (49 versus 29.3 months, $H R=0.74, p=0.03$ ) and progression-free survival $(\mathrm{HR}=0.70, p=0.006)$. Cetuximab has been shown to lyse cultured cervical cancer cells, which express a high level of EGFR by either cetuximab-mediated, compliment-dependent cellular cytotoxicity or antibody dependent cellular cytotoxicity [59]. Therefore, it could be a prime investigational agent either in combination with radiotherapy as primary treatment or in the treatment of recurrent cervical cancer.

Other biological targets exist including HER2/neu receptor but current studies have produced conflicting results about expression of this receptor and whether increased expression alters prognosis [63]. If increased expression of this receptor is definitively shown to be an adverse prognostic feature, lapatinib, an orally active small molecule dual tyrosine kinase inhibitor of both EGFR and HER2 [64] could be a promising new therapeutic agent against cervical cancer.

A major problem in conducting trials using new biological agents against cancer of cervix is cost. These agents are expensive and any studies would, at least in the UK, require support from the manufacturers. As the market for new agents in the treatment of cervical cancer is perceived to be too small to be commercially significant, currently, such support is absent. The annual incidence of this disease is only about 11,000 in the US [65] and about 3,000 in the UK [66]. However, in global terms, cervical cancer remains a very significant problem with an estimated incidence of 500,000 new cases per annum [1]. It is still the second most common female malignancy, and the most common female cancer in the 
developing world. Even if a worldwide vaccination programme, administered to girls aged 10 to 13 , started tomorrow, it would take several decades before this had any impact upon the occurrence of this disease. The incidence of cervical cancer remains high in countries such as India, Russia and Brazil [1], whose economies are rapidly expanding, making them potential markets for new agents. However, in Europe at least, one also has to overcome the commercial perceptions of the large pharmaceutical companies, as well as scientific challenges when planning new cervical cancer trials.

\section{Acknowledgements}

We are grateful to the UK Medical Research Council (MRC) for funding Jayne Tierney and supporting Claire Vale, and to the University of Leicester funding Paul Symonds. We also acknowledge the UK National Coordinating Centre for Research Capacity Development for funding Claire Vale via a fellowship. We thank Larysa Rydzewska, also funded by the MRC, for much help collating the manuscript. Finally, we would like to acknowledge the research institutions that conducted the trials described herein, and thank all the patients who took part in them. 


\section{References}

1. Parkin DM, Bray F, Ferlay J, Pisani Paola. Global cancer statistics, 2002. CA Cancer J Clin 2005;55:74-108.

2. Arbyn M, Raifu AO, Autier P, Ferlay J. Burden of cervical cancer in Europe: estimates for 2004. Ann Oncol 2007;doi:10.1093/annonc/mdm079.

3. Ries LAG, Harkins D, Krapcho M, Mariotto A, Miller BA, Feuer EJ et al. SEER Cancer Statistics Review, 1975-2003. National Cancer Institute, Bethesda, MD;Based on November 2005 SEER data submission,(Posted to the SEER website, 2006).

4. Eifel PJ, Berek JS, Thigpen JT. Gynecologic Cancers. Section 2. Cancer of the cervix, vagina, vulva. In: DeVita VT, Jr., Hellman S, Rosenberg SA, editors. Cancer: Principles \& Practice of Oncology. Sixth ed. Philadelphia: Lippincott-Raven; 2001. p. 1526-56.

5. Piver MS, Barlow JJ, Vongtama V, Webester J. Hydroxyurea and radiation therapy in advanced cervical cancer. Am J Obstet Gynecol. 1974;120:969-72.

6. Piver MS, Barlow JJ, Vongtama V, Blumenson L. Hydroxyurea as a radiation sensitizer in women with carcinoma of the uterine cervix. Am J Obstet Gynecol 1977;129:379-83.

7. Piver MS, Barlow JJ, Vongtama V, Blumenson L. Hydroxyurea: a radiation potentiator in carcinoma of the uterine cervix. A randomized double-blind study. Am J Obstet Gynecol 1983;147(7):803-8.

8. Piver M, Khalil M, Emrich LJ. Hydroxyurea plus pelvic irradiation versus placebo plus pelvic irradiation in nonsurgically staged stage IIIB cervical cancer. J Surg Oncol $1989 ; 42(2): 120-5$. 
9. Symonds R.P., Collingwood M, Kirwan J, Humber CE, Tierney JF, Green JA et al. Concomitant hydroxurea plus radiotherapy versus radiotherapy for carcinoma of the uterine cervix: a systematic review. Cancer Treat Rev 2004;30:405-14.

10. Hreshchyshyn MM , Aron BS, Boronow RC, Franklin EW, Shingleton HM, Blessing J.A. Hydroxyurea or placebo combined with radiation to treat stages IIIB and IV cervical cancer confined to the pelvis. Int J Radiat Oncol Biol Phys 1979;5:317-22.

11. Morris M, Eifel PJ, Lu J, Grigsby PW, Levenback C, Stevens RE et al. Pelvic radiation with concurrent chemotherapy compared with pelvic and para-aortic radiation for high-risk cervical cancer. N Engl J Med 1999;340:1137-43.

12. Rose PG, Bundy BN, Watkins EB, Thigpen JT, Deppe Gunther, Maiman MA et al. Concurrent cisplatin-based radiotherapy and chemotherapy for locally advanced cervical cancer. N Engl J Med 1999;340:1144-53.

13. Keys HM, Bundy BN, Stehman FB, Muderspach LI, Chafe WE, Suggs CL, III et al. Cisplatin, radiation and adjuvant hysterectomy compared with radiation and adjuvant hysterectomy for bulky stage IB cervical carcinoma. N Engl J Med 1999;340:1154-61.

14. Whitney CW, Sause W, Bundy BN, Malfetano JH, Hannigan EV, Fowler WC et al. Randomised comparison of fluorouracil plus cisplatin versus hydroxyurea in stage IIB/IVA in carcinoma of the cervix. J Clin Oncol 1999;17:1339-48.

15. Peters WA, Liu PY, Barrett RGW, Stock R, Berek F, DiSaia PJ et al. Cisplatin, 5Fluorouracil plus radiation therapy are superior to radiation therapy as adjunctive therapy in high risk, early stage carcinoma of the cervix after radical hysterectomy and pelvic lymphadenectomy: Report of a Phase III inter group study . Society of Gynecologic Oncologists 30th Annual Meeting 1999;February 5-9.

16. Green JA, Kirwan JM, Tierney JF, Symonds P, Fresco L, Collingwood M et al. 
Survival and recurrence after concomitant chemotherapy and radiotherapy for cancer of the uterine cervix: a systematic review and meta-analysis. Lancet 2001;358:781-6.

17. Lukka H, Hirte H, Fyles A, Thomas G, Elit G, Johnston M et al. Concurrent cisplatinbased chemotherapy plus radiotherapy for cervical cancer - a meta-analysis. Clin Oncol 2002;14:203-12.

18. Green J, Kirwan J, Tierney J, Vale C, Symonds P, Fresco L et al. Concomitant chemotherapy and radiation therapy for cancer of the uterine cervix. The Cochrane Database of Systematic Reviews 2005(Issue 3):CD002225.pub2.

DOI:10.1002/14651858.CD002225.pub2.

19. Chalmers I. The Cochrane Collaboration: preparing, maintaining and disseminating systematic reviews of the effects of health care. Annals of New York Academy of Sciences 1993;703:156-65.

20. Vale C, Tierney J, Stewart L. Concomitant chemoradiotherapy for cervical cancer: A systematic review and meta-analysis of individual patient data . Gynecol Oncol $2006 ; 100(2): 442-3$.

21. Vale CL. Concomitant chemoradiation in cervical cancer: a meta-analysis using individual patient data from randomised clinical trials . 15th Annual Meeting of the European Society of Gynaecological Oncology 2007:www.esgo.org/esgo15/program/session1/asp.

22. Eifel PJ, Winter K, Morris M, Levenback C, Grigsby PW, Cooper J et al. Pelvic irradiation with concurrent chemotherapy versus pelvic and para-aortic irradiation for high-risk cervical cancer: An update of Radiation Oncology Group Trial (RTOG) 9001. J Clin Oncol 2004;22:872-80.

23. Peters III WA, Liu PY, Barrett II RJ, Stock RJ, Bradley JM, Berek JS et al. Concurrent 
chemotherapy and pelvic radiation therapy compared with pelvic radiation therapy alone as adjuvant therapy after radical surgery in high-risk early-stage cancer of the cervix. J Clin Oncol 2000;18:1606-13.

24. Kantardzic N, Beslija S, Begic D. Comparison of parameters of myelotoxicity in patients treated with concomitant chemotherapy and radiotherapy versus radiotherapy alone. Medicinska Arhiv 2004;58(1):19-22.

25. Khalil A, Shamseddine A, Geara F, Charafeddine M, Seoud M. Concurrent chemoradio-therapy for locally advanced cervical cancer: A prospective randomized trial comparing Cis-platinum Vs Paclitaxel. Proceedings of the American Society of Clinical Oncology 2005. 23(No 16S), abs. 5163.

26. Kamnerdsupaphon P, Chitapanarux I, Sukthomya V, Lorvidhaya V. The 50-month results of the four non-platinum concurrent chemoradiation regimens for locally advanced cervical cancer. Proceedings of the American Society of Clinical Oncology 2007. 25(No 18S), abs. 5540.

27. Neoadjuvant Chemotherapy for Cervix Cancer Meta-analysis (NACCCMA) Collaboration. Neoadjuvant chemotherapy for locally advanced cervical cancer: A systematic review and meta-analysis of individual patient data from 21 randomised trials. Eur J Cancer 2003;39(17):2470-86.

28. Leborgne F, Leborgne JH, Doldán R, Zubizarreta E, Ortega B, Maisonneuve J et al. Induction chemotherapy and radiotherapy of advanced cancer of the cervix: a pilot study and phase III randomized trial. Int J Radiat Oncol Biol Phys 1997;37(2):343-50.

29. MRC СTO (CeCa). A study of potentially curative therapy alone or preceded by chemotherapy in the treatment of Stage Ib-IVa cervical carcinoma. Unpublished.

30. Sardi JE, Giaroli A, Sananes C, Ferreira M, Soderini A, Bermudez A et al. Long-term 
follow-up of the first randomized trial using neoadjuvant chemotherapy in Stage Ib squamous carcinoma of the cervix. The final results. Gynecol Oncol 1997;67:61-9.

31. Kumar L, Grover R, Pokharel YH, Chander S, Kumar S, Singh R et al. Neoadjuvant chemotherapy in locally advanced cervical cancer: two randomised studies. Aust N Z J Med 1998;28:387-90.

32. Tabata T, Takeshima N, Nishida H, Hirai Y, Hasumi K. A randomized study of primary bleomycin, vincristine, mitomycin and cisplatin (BOMP) chemotherapy followed by radiotherapy versus radiotherapy alone in stage IIIB and IVA squamous cell carcinoma of the cervix. Anticancer Res 2003;23(3C):2885-90.

33. Parmar MKB, Torri V, Stewart L. Extracting summary statistics to perform metaanalyses of the published literature for survival endpoints. Stat Med 1998;17:2815-34.

34. Tierney JF, Stewart LA, Ghersi D, Burdett S, Sydes MR. Practical methods for incorporating summary time-to-event data into meta-analysis. Trials 2007;8(1):16.

35. Rew DA, Wilson GD. Cell production rates in human tissues and tumours and their significance. Part II: clinical data. Eur J Surg Oncol 2000;26:405-17.

36. Bolger BS, Symonds RP, Stanton PD, MacLean AB, Burnett R, Kelly P et al. Prediction of radiotherapy response of cervical carcinoma through measurement of proliferation rate. $\mathrm{Br} \mathrm{J}$ Cancer 1996;74:1223-6.

37. Perez CA, Grigsby PWC-VH, Lockett MA. Carcinoma of the cervix. I. Impact of prolongation of overall treatment time and timing of brachytherapy on the outcome of radiation therapy. Int J Radiat Oncol Biol Phys 1995;32(5):1275-88.

38. Kigawa J, Minagawa $\mathrm{Y}$, Ishihara $\mathrm{H}$, Itamochi $\mathrm{H}$, Kanamori $\mathrm{Y}$, Terawaka $\mathrm{N}$. The role of neoadjuvant intra-arterial infusion chemotherapy with cisplatin and bleomycin for locally advanced cervical cancer. Am J Clin Oncol 1996;19(3):255-9. 
39. Sardi J, Giaroli A, Sananes C, Rueda NG, Vighi S, Ferreira M et al. Randomized trial with neoadjuvant chemotherapy in stage IIIB squamous carcinoma cervix uteri: an unexpected therapeutic management. International Journal of Gynecologic Cancer 1996;6:85-93.

40. Sardi JE, Sananes CE, Giaroli AA, Bermudez A, Ferreira M, Soderini AH et al. Neoadjuvant chemotherapy in cervical carcinoma stage IIB: a randomized controlled trial. International Journal of Gynecologic Cancer 1998;8:441-50.

41. Chang T-C, Lai C-H, Hong J-H, Hsueh S, Huang K-G, Chou H-H et al. Randomized trial of neoadjuvant cisplatin, vincristine, bleomycin, and radical hysterectomy versus radiation therapy for bulky stage Ib and IIA cervical cancer. J Clin Oncol 2000;18(8):1740-7.

42. Napolitano U, Imperato F, Mossa B, Framarino ML, Marziani R, Marzetti L . The role of neoadjuvant chemotherapy for squamous cell cervical cancer (Ib-IIIb): a long-term randomized trial. Eur J Gynaecol Oncol 2003;24(1):51-9.

43. Cai HB, Chen HZ, Yin HH. Randomized study of preoperative chemotherapy versus primary surgery for stage IB cervical cancer. J Obstet Gynaecol Res 2006;32(3):31523.

44. Katsumata N, Yoshikawa $\mathrm{H}$, Hirakawa $\mathrm{T}$ et al. Phase III randomized trial of neoadjuvant chemotherapy (NAC) followed by radical hysterectomy $(\mathrm{RH})$ versus $\mathrm{RH}$ for bulky stage I/II cervical cancer (JCOG 0102). Proceedings of the American Society of Clinical Oncology 2006. 24(No 18S), abs. 5013.

45. Eddy GL, Bundy BN, Creasman WT, Spirtos NM, Mannel RS, Hannigan E et al. Treatment of ("bulky") stage IB cervical cancer with or without neoadjuvant vincristine and cisplatin prior to radical hysterectomy and pelvic/para-aortic lymphadenectomy: a phase III trial of the gynecologic oncology group. Gynecol Oncol 2007;106(2):362-9. 
46. Eifel PJ, Moughan J, Erickson B, Iarocci T, Grant D, Owen J. Patterns of radiotherapy practice for patients with carcinoma of the uterine cervix: a patterns of care study. Int J Radiat Oncol Biol Phys. 2004;60:1144-53.

47. Barbera L, Paszat L, Thomas G, Covens A, Fyles A, Elit L et al. The rapid uptake of concurrent chemotherapy for cervix cancer patients treated with curative radiation. Int J Radiat Oncol Biol Phys 2006;64(5):1389-94.

48. Gaffney DK, Du Bois A, Narayan K, Reed N, Toita T, Pignata S et al. Practice patterns of radiotherapy in cervical cancer among member groups of the Gynecologic Cancer Intergroup (GCIG). Int J Radiat Oncol Biol Phys. 2007;68:485-90.

49. Pearcey R, Miao Q, Kong W, Zhang-Salomens J, MacKillop WJ. Impact of adoption of chemoradiotherapy on the outcome of cervical cancer in Ontario: Results of a population based cohort study. J Clin Oncol 2007;25(17):2383-8.

50. Lanciano RM, Calkins A, Bundy BN, Parham G, Lucci JA, Moore DH et al. Randomized comparison of weekly cisplatin or protracted venous infusion of Fluorouracil in combination with pelvic radiation in advanced cervical cancer: a Gynecologic Oncology Group study. J Clin Oncol 2005;23(33):8289-95.

51. Buda A, Fossati R, Colombo N, Fei F, Floriani I, Gueli Alletti D et al. Randomized trial of neoadjuvant chemotherapy comparing paclitaxel, ifosfamide, and cisplatin with ifosfamide and cisplatin followed by radical surgery in patients with locally advanced squamous cell cervical carcinoma: the SNAP01 (Studio Neo-Adjuvante Portio) Italian Collaborative Study. J Clin Oncol 2005;23(18):4137-45.

52. Glynne-Jones R, Hoskin P. Neoadjuvant cisplatin chemotherapy before chemoradiation: a flawed paradigm? J Clin Oncol 2007;25(33):5281-6.

53. Monk BJ, Wang J, Im S, Stock RJ, Peters WA, Liu PY et al. Rethinking the use of 
radiation and chemotherapy after radical hysterectomy: a clinical-pathologic analysis of a Gynecologic Oncology Group/Southwest Oncology Group/Radiation Therapy Oncology Group trial. Gynecol Oncol. 2005;96:721-8.

54. Dreicer R. Chemotherapy for muscle-invasive bladder cancer in the perioperative setting: current standards. Urologic Oncology 2007;25(1):72-5.

55. Stokes Z, Symonds P, Habeshaw T, Reed N, Curto J, Joynson C et al. Phase one dose finding study of capecitabine (Xeloda), radiotherapy and cisplatin in the treatment of locally advanced squamous cervical cancer. Gynecol Oncol 2005;97(3):790-5.

56. Long HJ, Bundy BN, Grendys EC, Benda JA, McMeekin DS, Sorosky J et al. Randomized phase III trial of cisplatin with or without topotecan in carcinoma of the uterine cervix: a Gynecologic Oncology Group Study. J Clin Oncol 2005;23(21):462633.

57. Vandenput I, Amant F, Neven P, Berteloot P, Leunen K, Vergote I. Effectiveness of weekly topotecan in patients with recurrent epithelial ovarian cancer. International Journal of Gynecological Cancer 2007;17(1):83-7.

58. Cerciello F, Riesterer O, Sherweif M, Odermatt B, Ciernik IF. Is EGFR a moving target during radiotherapy of carcinoma of the uterine cervix? Gynecol Oncol 2007;106(2):394-9.

59. Bellone S, Frera G, Landolfi G, Romani C, Bandiera E, Tognon G et al. Overexpression of epidermal growth factor type-1 receptor (EGF-R1) in cervical cancer: implications for Cetuximab-mediated therapy in recurrent/metastatic disease. Gynecol Oncol 2007;106(3):513-20.

60. Kersemaekers AM, Fleuren GJ, Kenter GG, Van den Broek LJ, Uljee SM, Hermans J 
et al. Oncogene alterations in carcinomas of the uterine cervix: overexpression of the epidermal growth factor receptor is associated with poor prognosis. Clin Cancer Res 1999;5(3):577-86.

61. Kim GE, Kim YB, Cho NH, Chung HC, Pyo HR, Lee JD et al. Synchronous coexpression of epidermal growth factor receptor and cyclooxygenase-2 in carcinomas of the uterine cervix: a potential predictor of poor survival. Clin Cancer Res 2004;10 (4):1366-74.

62. Bonner JA, Harari PM, Giralt J, Azarnia N, Shin DM, Cohen RB et al. Radiotherapy plus cetuximab for squamous-cell carcinoma of the head and neck. N Engl J Med 2006;354(6):567-78.

63. Nadler LM, Botnick L, Finberg R, Canellos GP, Takvorian T, Bast RC et al. Anti-B1 monoclonal antibody and complement treatment in autologous bone-marrow transplantation for relapsed b-cell non-hodgkin's lymphoma. Lancet.

64. Burstein HJ, Storniolo AM, Franco S, Forster J, Stein S, Rubin S et al. A phase II study of lapatinib monotherapy in chemotherapy-refractory HER2-positive and HER2negative advanced or metastatic breast cancer. Ann Oncol 2008;Advanced Access:doi:10.1093/annonc/mdm601.

65. Jemal A, Siegel R, Ward E, Murray T, Xu J, Thun MJ. Cancer Statistics, 2007. CA Cancer J Clin 2007;57:43-66.

66. Toms JR. Cancerstats Monograph 2004. ed. London: Cancer Research UK; 2004.

67. Symonds R.P., Collingwood M, Kirwan J, Humber CE, Tierney JF, Green JA et al. Concomitant hydroxurea plus radiotherapy versus radiotherapy for carcinoma of the uterine cervix: a systematic review. Cochrane Database of Systematic Reviews 2004(1):CD003918. 
68. Piver SM, Vongtama V, Emrich LJ. Hydroxyurea plus pelvic radiation versus placebo plus pelvic radiation in surgically stages stage IIIB cervical cancer. J Surg Oncol $1987 ; 35: 129-34$

69. Madoc-Jones $\mathrm{H}$, Perez $\mathrm{C}$, Camel M, Jennings F. Preliminary experience in a prospective randomized trial to assess the value of hydroxyurea in addition to conventional radiotherapy in the management of advanced stages of carcinoma of the uterine cervix. Int J Radiat Oncol Biol Phys 1980;6(10):1430.

70. Wong LC, Choo YS, Choy D, Sham JST, Ma HK. Long-term follow-up of potentiation of radiotherapy by cis-platinum in advanced cervical cancer. Gynecol Oncol $1989 ; 35: 159-63$

71. Onishi $\mathrm{H}$, Yagamushi M, Kuriyama $\mathrm{K}$ et al. Effect of concurrent intra-arterial infusion of platinum drugs for patients with stage III or IV uterine cervical cancer treated with radiotherapy. Cancer J Sci Am 99. 5, 40-45.

72. Lira Puerto V, De la Huerta R, Cortes H, Fernandez A, Silva A, Martinez R et al. Cisplatin (CDDP) plus radiotherapy (RT) vs radiotherapy alone in locally advanced cervical cancer. Proceedings of the American Society of Clinical Oncology 1990;9:A633.

73. Tseng C-J, Chang-Ting C, Chyong-Huey L, Soong Y-K, Hong J-H, Tang SG et al. A randomized trial of concurrent chemoradiotherapy versus radiotherapy in advanced carcinoma of the cervix. Gynecol Oncol 1997;66:52-8.

74. Pearcey R, Brundage M, Drouin P, Jeffrey J, Johnston D, Lukka H et al. Phase III Trial Comparing Radical Radiotherapy With and Without Cisplatin Chemotherapy in Patients With Advanced Squamous cell Cancer of the Cervix. J Clin Oncol 2002;20(4):966-72. 
75. Chen H-W, Jun-Jei, Luo Wei, et al. A randomized trial of hyperthermoradiochemotherapy for uterine cervix cancer. Chinese Journal of Oncology $1997 ; 24: 249-51$

76. Garipagaoglu M, Kayikcioglu F, Kose MF, Adli M, Gulkesen KH, Kocak Z et al. Adding concurrent low dose continuous infusion of cisplatin to radiotherapy in locally advanced cervical carcinoma: a prospective randomized pilot study. $\mathrm{Br} \mathrm{J}$ Radiol 2004;77:581-7.

77. Singh TT, Singh IY, Sharma DT, Singh N. Role of chemoradiation in advanced cervical cancer. Indian J Cancer 2003;40(3):101-7.

78. Mitra D, Ghosh B, Kar A, Basu S, Deb AR, Sur PK. Role of chemoradiotherapy in advanced carcinoma cervix. J Indian Med Assoc 2006;104(8):432-8.

79. Kumar ES, Lal P, Tiwari A, Kumar S, Dimri K, Rastogi $\mathrm{N}$ et al. Chemo-irradiation versus radiotherapy alone in locally advanced carcinoma of the uterine cervix - An ongoing phase III trial. 23rd ESTRO (2004 Amsterdam): Abstract 673.

80. Cikaric S, Petrovic-Stupar S, Marjanov I, Rudan L, Colakovic S, Tomasevic A et al. Radiotherapy vs. radiotherapy + chemotherapy of advanced cervical cancer: regression of tumour, early and late sequalaes, relapses of disease and 3 years survival (the third phase). European Journal of Cancer Supplements 2005;3(2):266.

81. Bulnes R, Rivera R. Carcinoma Epidermoide del cervix uterino: Tratamiento con radiotherapia y quimioterapia asociadas. Prensa Med Argent 1986;73(3):100-3.

82. Hernandez JRA, Rafael de la Huerta S, Canfield FM, Orozco AF. Cáncer cervicouterino. Etapa clínica III. Tratamiento combinado de radioterapia quimioterapia. Ginecología y obstetricia de mexico 1991;59:238-42.

83. Wong LC, Ngan ANY, Cheung ANY, Cheng DKL, Ng TY, Choy DTK. Chemoradiation 
and adjuvant chemotherapy in cervical cancer. J Clin Oncol 1999;17(7):2055-60.

84. Lorvidhaya V, Chitapanarux I, Sangruchi S, Lertsanguansinchai P, Konthanarat $Y$, Tangkarrat S et al. Concurrent Mitomycin C, 5-Fluorouracil, and radiotherapy in the treatment of locally advanced carcinoma of the cervix: a randomized trial. Int J Radiat Oncol Biol Phys 2003;55(2):1226-32.

85. Thomas G, Dembo A, Ackerman I, Franseen E, Balogh J, Fyles A et al. A randomized trial of standard versus partially hyperfractionated radiation with or without concurrent 5-fluorouracil in locally advanced cervical cancer. Gynecol Oncol 1998;69:137-45.

86. Fernandez DJ, Vidyasagar MS, Rao KK, Shenoy A, Kasturi DP. Synchronous 5fluorouracil, mitomycin-c and radiation therapy in the treatment of locally advanced carcimoma od the cervix. Proceedings of the 16th Annual Meeting of the Association of Radiation Oncologists of India 1995;Kerala:97-103.

87. Roberts KB, Urdaneta N, Vera Raul, Vera Andres, Gutierrez E, Aguilar Yadelis et al. Interim results of a randomized trial of mitomycin $\mathrm{C}$ as an adjunct to radical radiotherapy in the treatment of locally advnaced squamous-cell carcinoma of the cervix. International Journal of Cancer (Radiat. Oncol. Invest.) 2000;90:206-23.

88. Chauvergne J, Lhomme C, Rohart J, Héron JF, Aymé Y., Goupil A. et al. Chimiothérapie néoadjuvante des cancer du col utérin aux stades IIb e III. Résultats éloignés d'un essai randomisé pluricentrique portant sur 151 patients. Bull Cancer (Paris) 1993;80:1069-79.

89. Souhami L, Gil RA, Allan SE, Canary PV, Araújo CMM, Pinto LHJ et al. A randomized trial of chemotherapy followed by pelvic radiation therapy in Stage IIIB carcinoma of the cervix. J Clin Oncol 1991;9(6):970-7. 
90. Tattersall MHN, Ramirez C, Coppleson M. A randomized trial comparing platinumbased chemotherapy followed by radiotherapy alone in patients with locally advanced cervical cancer. International Journal of Gynecologic Cancer 1992;2:244-51.

91. Herod J, Burton A, Bixton J, Tobias J, Luesley D, Jordan S et al. A randomised prospective phase III clinical trial of primary bleomycin, ifosfamide and cisplatin (BIP) chemotherapy followed by radiotherapy versus radiotherapy alone in operable cancer of the cervix. Ann Oncol 2000;11:1175-81.

92. Cárdenas J, Olguín A, Figueroa F, Peña J, Beccerra F, Huizar R. A randomized trial of chemotherapy (CT) followed by radiotherapy (RT) vs radiotherapy alone in Stage IIIb cervical carcinoma: preliminary results. Fourth International Congress on Anticancer Chemotherapy 1993:87.

93. Cárdenas J, Olguín A, Figueroa F, Beccerra F, Huizar R. Randomized neoadjuvant chemotherapy in cervical carcinoma stage Ilb. PEC+ RT vs RT. Proceedings of the American Society of Clinical Oncology 1991;10:189, A620.

94. Chiara S, Bruzzone M, Merlini L, Bruzzi P, Rosso R, Franzone P et al. Randomized study comparing chemotherapy plus radiotherapy versus radiotherapy alone in FIGO stage IIB-III cervical carcinoma. Am J Clin Oncol 1994;17(4):294-7.

95. Sundfor K, Tropé CG, Högberg T, Onsrud M, Koern J, Simonsen E et al. Radiotherapy and neoadjuvant chemotherapy for cervical carcinoma. A randomized multicenter study of sequential cisplatin and 5-fluorouracil and radiotherapy in advanced cervical carcinoma Stage 3B and 4A. Cancer 1996;77:2371-8.

96. Tattersall MHN, Lorvidhaya V, Vootiprux V, Cheirsilpa A, Wong F, Azhar T et al. Randomized trial of epirubicin and cisplatin chemotherapy followed by pelvic radiation in locally advanced cervical cancer. J Clin Oncol 1995;13(2):444-51. 
97. Symonds RP, Habeshaw T, Reed NS, Paul J, Pyper E, Yosef H et al. The Scottish and Manchester randomised trial of neo-adjuvant chemotherapy for advanced cervical cancer. Eur J Cancer 2000;36:994-1001.

98. Benedetti-Panici P, Greggi S, Colombo A, Amoroso M, Smaniotto D, Gianarelli D et al. Neoadjuvant chemotherapy and radical surgery versus exclusive radiotherapy in locally advanced cervical cancer: Results from the Italian multicenter randomised study. J Clin Oncol 2002;20(1):179-88.

99. Park SY, Kim JH, Kim BG, Lee KH, Park KB, Lee BH et al. Phase III randomized study of MVC intraarterial (arm 1), or systemic (arm 2) neoadjuvant chemotherapy versus radiation therapy only (arm3) for stage IIb bulky carcinoma of uterine cervix: preliminary report. Proceedings of the American Society of Clinical Oncology 1996;15:302, A840. 